\title{
Ambulatory education in clinics from the perspective of medical students in Iran, 2016
}

\author{
Parastoo Baharvand ${ }^{1}$
}

\begin{abstract}
Introduction: Recent years have seen a growing attention to the function and position of ambulatory care and clinical education in medical education. The present study was conducted to investigate the current status of the quality of education in major clinics from the perspective of medical students. Method: This cross-sectional study was conducted in 2016 on 300 medical student from Lorestan University of Medical Sciences who selected through census method. Data were collected using a researcher-made questionnaire with a confirmed face and content validity and a reliability of 0.85 . The data were analyzed in SPSS-21 using descriptive and analytical statistics.

Results: The study participants included clerkship students (65.9\%) and interns (34.1\%) with a mean age of $22 \pm 2.1$ and $24 \pm 3.5$ years respectively. Statistically significant difference was observed between teachers' quality of teaching and other domains from the perspective of the clerkship students. From the interns' perspective, teachers' quality of teaching and duration of attending clinics were the domains with significant statistical differences among clinics. $(P<0.05)$. According to the assessments by the clerkship students and interns, the mean score in obstetrics clinics, was lower than other clinics.
\end{abstract}

Conclusion: Given the results obtained, particularly on teachers' quality of teaching, teachers are respectfully recommended to pay a special attention to clinical education, enthusiastically involve students in patient-associated issues and improve their skills using modern educational methods.

Keywords: quality, clinical education, medical students

\section{INTRODUCTION}

Clinical education should be properly implemented as a foundation of medicine or will face problems in more advanced stages. Although inpatients' bedside teaching used to constitute the main part of clinical education, it failed to familiarize learners with publicly known health problems (1). Given the need for educational systems to train students according to future occupational requirements and graduates' achievements (2), new attitudes have been adopted towards outpatient treatment diagnostic, therapeutic and advisory services for outpatients, clinics provide the learning and teaching opportunity for the learners (5). Clinical education refers to any kind of learning achieved in clinics for prevention, diagnosis, treatment or follow-up during visiting and providing advice to outpatients $(5,6)$. The function and position of outpatient care and clinical education in medical education has been stressed in recently conducted studies in both Iran and around the world (7-15). Jacobson found more positive attitudes in students towards clinical education compared to interdisciplinary education (16). The educational challenges reflected as suboptimal quality of clinical education in the literature (7-9) include patient diversity, an imbalance between the services provided for patients and the training offered to students and also between the number of students and the available clinical facilities and equipment. Irby described the clinical education performance as suboptimal by comparing it with interdisciplinary education (17). The studies conducted in Iran also revealed shortcomings in this educational area (7-15). Given that investigating the current status and the strengths and weaknesses of the program in learners' perspective plays a key role in improving the quality of education, the present study was conducted to investigate the quality of clinical education from the perspective of clerkship students and interns and to help those involved in education with making better

\footnotetext{
1 Assistant professor, Department of Social Medicine, School of Medicine, Lorestan University of Medical Sciences, Khorramabad, Iran
}

Correspondence: Parastoo Baharvand

Assistant professor, Department of Social Medicine, School of Medicine, Lorestan University of Medical Sciences, Khorramabad, Iran

Received: 22 Feb 2018, Accepted: 9 Apr 2018

E-mail: Dr.baharvand@gmail.com

(C) 2018 by the authors; licensee Modestum Ltd., UK. This article is an open access article distributed under the terms and conditions of the Creative Commons Attribution License (http://creativecommons.org/licenses/by/4.0/). 
Table 1: The mean score of different dimensions of clinical education from the interns and clerkship students' perspective

\begin{tabular}{|c|c|c|c|c|c|c|c|}
\hline $\begin{array}{l}\text { MEDICAL } \\
\text { STUDENTS }\end{array}$ & Clinic & $\begin{array}{c}\text { Teachers' quality } \\
\text { of teaching } \\
\text { Mean } \pm \text { SD }\end{array}$ & $\begin{array}{c}\text { Clinic's } \\
\text { facilities } \\
\text { Mean } \pm \text { SD }\end{array}$ & $\begin{array}{c}\text { Patient-associated } \\
\text { issues } \\
\text { Mean } \pm \text { SD }\end{array}$ & $\begin{array}{l}\text { Duration of } \\
\text { attending clinics } \\
\text { Mean } \pm \text { SD }\end{array}$ & $\begin{array}{c}\text { The number of } \\
\text { students in the } \\
\text { program }\end{array}$ & $\begin{array}{l}\text { Total Score } \\
\text { Mean } \pm \text { SD }\end{array}$ \\
\hline \multirow{5}{*}{$\begin{array}{l}\text { clerkship } \\
\text { students' }\end{array}$} & Pediatric & $42.3 \pm 5.1$ & $9.9 \pm 3.7$ & $11.2 \pm 2$ & $6.8 \pm 2.09$ & $6.8 \pm 1.7$ & $70.1 \pm 8.4$ \\
\hline & Surgery & $43.6 \pm 5.3$ & $11.4 \pm 4$ & $11.3 \pm 2.1$ & $6.8 \pm 2$ & $7 \pm 1.7$ & $78.8 \pm 8.15$ \\
\hline & Internal & $40.5 \pm 5.1$ & $11 \pm 4.02$ & $11 \pm 2.2$ & $6.6 \pm 1.9$ & $6.3 \pm 1.8$ & $65.5 \pm 8.3$ \\
\hline & Obstetrics & $31.7 \pm 5.2$ & $9 \pm 4$ & $10.4 \pm 1.9$ & $5.7 \pm 2$ & $7 \pm 2$ & $54.4 \pm 8.4$ \\
\hline & $\mathbf{P}$ & 0.001 & 0.19 & 0.07 & 0.21 & 0.09 & 0.034 \\
\hline \multirow{5}{*}{ interns } & Pediatric & $49.01 \pm 4.1$ & $13.2 \pm 3.6$ & $12 \pm 1.9$ & $7.8 \pm 1$ & $7.8 \pm 1.5$ & $74.7 \pm 8.2$ \\
\hline & Surgery & $41.4 \pm 4.1$ & $12.4 \pm 3.5$ & $11.2 \pm 1.6$ & $6.8 \pm 1.07$ & $7.2 \pm 1.5$ & $73.9 \pm 8$ \\
\hline & Internal & $48.8 \pm 4.3$ & $13 \pm 3.1$ & $11.1 \pm 2.1$ & $7.3 \pm 1.1$ & $6.9 \pm 1.6$ & $69.9 \pm 8.5$ \\
\hline & Obstetrics & $39.9 \pm 4.01$ & $11.8 \pm 3.7$ & $10.1 \pm 2.2$ & $5.4 \pm 1.2$ & $6.7 \pm 1.8$ & $49.9 \pm 8.01$ \\
\hline & $\mathbf{P}$ & 0.03 & 0.17 & 0.11 & 0.04 & 0.321 & 0.021 \\
\hline
\end{tabular}

educational decisions and plans for further educational improvement.and community-based learning in most medical schools $(3,4)$. In addition to providing.

\section{MATERIALS AND METHODS}

\section{Participants and Setting}

The present descriptive cross-sectional study was conducted in 2016 academic year on 300 medical clerkship students and interns in Lorestan University of Medical Sciences. The census method was used to sample all eligible candidates including students passing at least one month of their program. The exclusion criteria comprised unwillingness to participate in the study and failure to complete or return the questionnaires. Ethical principles such as protecting the subjects' anonymity were also observed.

\section{Data Collection Instrument}

The data collection tools consisted of researcher-made questionnaires comprising demographic information and 23 items on five domains. These domains included teachers' quality of teaching (12 items), clinic's facilities and equipment (4 items), patient-associated issues ( 3 items), duration of attending clinics ( 2 items) and the number of students in each program ( 2 items). Of the 23 items, prescription-associated items addressed only the interns. The items were scored on a five-point scale including very poor (score 1) to very good (score 5). The overall score of the questionnaire thus ranged between 23 and 115. The content and face validity of the tool was confirmed by a review of literature and through a survey of medical education experts and university professors whose modifying and supplementary views helped compile the final questionnaire. The construct validity of the tool was assessed using an exploratory factor analysis, in which the items expressing similar concerns were taken as one dimension and the domains that covered most of the variance were put together in such a way that the domains had the lowest and their items the highest correlation A pilot study was conducted and the questionnaires were distributed among 45 students, including 30 clerkship students and 15 interns, to resolve the potential design problems before finalizing the questionnaires. After making the necessary modifications, a reliability coefficient of 0.85 obtained through the test-retest three weeks later confirmed the reliability of the questionnaire and a Cronbach's alpha calculated as 0.91 confirmed the internal consistency of the tool.

\section{Statistical analysis}

The data obtained were analyzed and explained in SPSS-22 using descriptive statistics, including mean, standard deviation and frequency, and analytical statistics including the t-test, the one-way ANOVA and followed by the Tukey's post-hoc test and the Chi-square. $\mathrm{P}<0.05$ was set as the level of statistical significance.

\section{RESULTS}

With a response rate of $92 \%, 22$ partially-completed questionnaires were excluded in a total of 300 handed-out questionnaires. The students comprised 180 women and 98 men, including 183 (60.9\%) clerkship students and 95 (34.1\%) interns with a mean age of $24 \pm 4.2$ and $24 \pm 3.5$ years respectively. Table 1 presents the results associated with the interns and clerkship students' perspective on the current status of different dimensions of clinical education. The mean score of teachers' quality of teaching was the only dimension of clinical education with statistically significant differences in pediatric and surgery clinics compared to in obstetrics 
Table 2: The mean score of different dimensions of clinical education from the interns' perspective

\begin{tabular}{|c|c|c|c|c|c|c|}
\hline Clinic & $\begin{array}{c}\text { Teachers' quality of } \\
\text { teaching } \\
\text { Mean } \pm \text { SD }\end{array}$ & $\begin{array}{c}\text { Clinic's facilities } \\
\text { Mean } \pm \text { SD }\end{array}$ & $\begin{array}{c}\text { Patient-associated } \\
\text { issues } \\
\text { Mean } \pm \text { SD }\end{array}$ & $\begin{array}{l}\text { Duration of } \\
\text { attending clinics } \\
\text { Mean } \pm \text { SD }\end{array}$ & $\begin{array}{c}\text { The number of students } \\
\text { in the program } \\
\text { Mean } \pm \text { SD }\end{array}$ & $\begin{array}{l}\text { Total Score } \\
\text { Mean } \pm \text { SD }\end{array}$ \\
\hline Pediatric & $49.01 \pm 4.1$ & $13.2 \pm 3.6$ & $12 \pm 1.9$ & $7.8 \pm 1$ & $7.8 \pm 1.5$ & $74.7 \pm 8.2$ \\
\hline Surgery & $41.4 \pm 4.1$ & $12.4 \pm 3.5$ & $11.2 \pm 1.6$ & $6.8 \pm 1.07$ & $7.2 \pm 1.5$ & $73.9 \pm 8$ \\
\hline Internal & $48.8 \pm 4.3$ & $13 \pm 3.1$ & $11.1 \pm 2.1$ & $7.3 \pm 1.1$ & $6.9 \pm 1.6$ & $69.9 \pm 8.5$ \\
\hline Obstetrics & $39.9 \pm 4.01$ & $11.8 \pm 3.7$ & $10.1 \pm 2.2$ & $5.4 \pm 1.2$ & $6.7 \pm 1.8$ & $49.9 \pm 8.01$ \\
\hline $\mathbf{P}$ & 0.03 & 0.17 & 0.11 & 0.04 & 0.321 & 0.021 \\
\hline
\end{tabular}

Table 3: The absolute and relative frequency of the variables reflecting the quality of clinical education from the perspective of the clerkship students and interns

\begin{tabular}{|c|c|c|c|c|c|}
\hline Variable & Very poor & Poor & Moderate & Good & Very good \\
\hline Access to scientific resources & $28(10 \%)$ & $51(18.3 \%)$ & $72(25.8 \%)$ & $56(20.1 \%)$ & $71(25.5 \%)$ \\
\hline Physical conditions & $32(11.5 \%)$ & $70(25.1 \%)$ & 85 (30.5\%) & $60(21.9 \%)$ & $31(11.1 \%)$ \\
\hline Facilities & $28(10 \%)$ & $66(23.7 \%)$ & 106 (38.1\%) & $65(23.3 \%)$ & $13(4.9 \%)$ \\
\hline Number of patients & 109 (39.1\%) & $113(40.5 \%)$ & $41(14.7 \%)$ & $11(4.3 \%)$ & $4(1.4 \%)$ \\
\hline Patient diversity & $41(14.7 \%)$ & $152(54.6 \%)$ & $51(18.2 \%)$ & 25 (9.3\%) & $9(3.2 \%)$ \\
\hline Patient cooperation & 47 (16.9\%) & $134(48.2 \%)$ & $58(20.8 \%)$ & $23(8.2 \%)$ & $16(5.9 \%)$ \\
\hline Educational targets & $41(14.7 \%)$ & 99 (35.6\%) & 107 (38.4\%) & $20(7.4 \%)$ & $11(3.9 \%)$ \\
\hline Communication with patients & $43(15.5 \%)$ & $88(31.6 \%)$ & 108 (38.7\%) & $22(7.9 \%)$ & $17(6.3 \%)$ \\
\hline History taking training & $43(15.5)$ & $94(33.8 \%)$ & $102(36.6 \%)$ & $26(9.2 \%)$ & $13(4.9 \%)$ \\
\hline Feedback provision & $38(13.6 \%)$ & $90(32.3 \%)$ & 107 (38.4\%) & $29(10.7 \%)$ & $14(5 \%)$ \\
\hline Duration of residency & $48(17.2 \%)$ & $113(40.5 \%)$ & $78(28 \%)$ & $21(7.5 \%)$ & $18(6.8 \%)$ \\
\hline Adequacy of training & $41(14.7 \%)$ & $99(35.6 \%)$ & $84(30.1 \%)$ & $28(10.4 \%)$ & $26(9.2 \%)$ \\
\hline Opportunity for independent visits & $46(16.5 \%)$ & $70(25.2 \%)$ & $85(30.6 \%)$ & $45(16.2 \%)$ & $32(11.5 \%)$ \\
\hline Opportunity for Prescription & $20(7.2 \%)$ & $39(14 \%)$ & $80(28.6 \%)$ & $47(17.2 \%)$ & $92(33 \%)$ \\
\hline Cooperation of staff & 27 (9.7\%) & 45 (16.2\%) & $66(24 \%)$ & $59(21.1 \%)$ & $81(29 \%)$ \\
\hline Number of clerkship students & $42(15.3 \%)$ & 87 (31.2\%) & $119(42.8 \%)$ & $21(7.5 \%)$ & 9 (3.2\%) \\
\hline Number of interns & $42(15.3 \%)$ & $68(24 \%)$ & 135 (48.5\%) & $24(9 \%)$ & $9(3.2 \%)$ \\
\hline Teachers' commitment to training & $41(14.7 \%)$ & $96(34.4 \%)$ & 75 (26.9\%) & $43(15.8 \%)$ & $23(8.2 \%)$ \\
\hline Time management training & $33(12.1 \%)$ & $69(24.8 \%)$ & 109 (39.1\%) & $34(12.2 \%)$ & $33(11.8 \%)$ \\
\hline Presenting structured discussions & $32(12.1 \%)$ & $68(24.4 \%)$ & $112(40.2 \%)$ & $31(10.8 \%)$ & $35(12.5 \%)$ \\
\hline Presenting differential diagnosis & $29(10.4 \%)$ & $76(27.2 \%)$ & $93(33.7 \%)$ & $34(12.2 \%)$ & $46(16.5 \%)$ \\
\hline Needs assessment & $31(11.1 \%)$ & $58(20.8 \%)$ & $101(36.6 \%)$ & $39(14 \%)$ & 49 (17.5\%) \\
\hline Interest in teaching & $41(14.7 \%)$ & 78 (28.2\%) & 97 (34.8\%) & $30(10.8 \%)$ & 32 (11.5\%) \\
\hline
\end{tabular}

clinics $(P<0.05)$; the highest mean score was found in surgery clinics and the lowest in obstetrics clinics (Table 2).

The comparison of the domain maen score of the questionnaire from the interns' perspective showed, teachers' quality of teaching and duration of attending clinics were the only domains with significant statistical differences among clinics. The mean score of teachers' quality of teaching was higher in the pediatric clinic and the mean score of duration of attending clinics was, lower in Obstetrics clinic, Other domains were not significantly different among clinics. Gender was also found not to be significantly different in the learners' view.

As seen in Table 3, which presents the frequency of variables that reflect the quality of education in all the study clinics from the perspective of the clerkship students and interns, the number of patients, patient diversity and cooperation, teachers' commitment to training as well as adequacy of training were evaluated as poor, while cooperation of staff was rated as very good.

\section{DISCUSSION}

The present study was conducted to investigate the viewpoint of medical students enrolled in clerkship and internship programs about clinical education.

The results obtained revealed differences between clinics in some dimensions of the quality of education, particularly in teachers' quality of clinical teaching, in view of both clerkship students and interns. Amini reported no positive attitudes in clerkship students and interns towards teachers' performance as poor or moderate by the participants. Mortazavi et al. were the only authors reporting the greatest satisfaction with teachers' quality of teaching in clerkship students and interns working in outpatient departments (14). The present study however indicated little attention paid to this issue by the teachers, as reflected in the poor assessments made by the interns. 
Obtaining an accurate patient history with a focus on their problem as well as conducting short and thorough examinations is a basic responsibility of general practitioners, as emphasized by Masood et al. (18). Teaching how to communicate with patients to obtain their history therefore constitutes another domain of teachers' quality of teaching. This can be achieved if physicians can effectively communicate with patients, as suggested in the studies conducted by Zali et al. (19), Kalet et al. (20) and Sievers (21). Teachers' lack of interest in clinical education, probably as a result of inadequate motivation, was also rated poor by the clerkship students, which is consistent with similar studies $(7,10,12)$. In order to improve teachers' performance and overcome their obstacles to ambulatory care education, proper measures and interventions should be adopted to improve the teachers' knowledge and attitude towards clinical education. To motivate teachers, Scott suggested that the annual promotion of teachers be based on regular and frequent evaluations of their educational performance (22).

Patient-associated issues, including the number and diversity of patients as well as patient cooperation during examinations and history taking, was rated as poor by the participants in all of the clinics, which is also consistent with the studies conducted by Khorasani et al. (12) and Avizhgan (10). Specific programs are therefore required to be designed as a model for future occupational environments to expand the range of educational clinic patients.

According to the interns, there are statistically significant differences between different clinics in terms of the mean score of duration of attending clinics, evaluated as inadequate particularly in obstetrics clinics, as was the case in the studies conducted by Shams et al., Avizhgan et al. and Khorasani et al. (10-12).

Amini et al. also identified inadequate time allocated by teachers and their failure to be present full-time as the main drawbacks of ambulatory clinics. Lesky et al. studied the educational challenges of medical students at outpatient centers and reported inadequate duration of training as an obstacle to ambulatory education (23).

Based on the results obtained, the ambulatory education program is recommended to be modified to maximize its applicability for learners. Teachers can help solve the inevitable problem of clinic overcrowding so as to both enable clinical ambulatory education and address patient-associated issues.

Cooperation of health staff was found to be a strength of educational clinics and evaluated as very good by the participants owing to having the score of work clearly defined for the personnel, which is however inconsistent with the poorly-rated cooperation of staff in the study of Anbari et al. (13). The present study interns identified excessively high number of clerkship students compared to the clinical capacity, which is consistent with the study conducted by Avizhgan et al. (10). As stated earlier, the number of students present in the clinic should be balanced by the improved physical environment of the clinic to enhance the quality of education and avoid education disruptions. From the view of the clerkship students and interns, the quality of clinical education received the lowest mean score in obstetrics clinics compared to in the other clinics, as the learners rated teachers' quality of teaching as poor, probably due to inadequate motivation or poor attitudes in teachers towards clinical education. All dimensions of the quality of clinical education were rated as poor or moderate by the learners except for a single item. Khorasani reported overall negative attitudes towards the current status of clinical education (12) and Alizadeh suggested that the present clinical education system does not meet the future requirements of physicians (24). Wolpaw reported partial satisfaction with ambulatory education (25), while Lubetkin reported a poor quality of education (26).

All this evidence suggests the lack of an integrated clinical education program for properly meeting the learners' needs. Teachers are respectfully recommended to pay a special attention to clinical education, enthusiastically involve students in patient-associated issues and improve their skills using modern educational methods.

Failing to investigate other types of clinics and teachers' comments was a limitation of the present study.

\section{CONCLUSION}

Education planners are required to observe the educational principle of making a balance between the number of students and the facilities available, to design comprehensive programs for expanding the number and diversity of patients in educational clinics and to do their best to turn the clinical setting to a model of the future occupational environment for physicians. To maximize the quality of education, teachers are recommended to involve the students in patient-associated issues while considering the learners' educational needs. 


\section{REFERENCES}

1. Regan-Smith M, Young WW, Keller AM. An efficient and effective teaching model for ambulatory education. Acad Med. 2002;77(7):593-9. https://doi.org/10.1097/00001888-200207000-00003

2. Mazor KM, Stone SL, Carlin M, Alper E. What do medicine clerkship preceptors do best? Acad Med. 2002;77(8):837-40. https://doi.org/10.1097/00001888-200208000-00018

3. Krackov Sh K. Perspectives on Ambulatory Programs: Barriers and Implementation Strategies. Teaching \& Learning in Medicine. 1993;5(4):243-50. https://doi.org/10.1080/10401339309539631

4. Delva MD, Schultz KW, Kirby JR, Godwin M. Ambulatory teaching: do approaches to learning predict the site and preceptor characteristics valued by clerks and residents in the ambulatory setting? BMC Med Educ. 2005;5:35. https://doi.org/10.1186/1472-6920-5-35

5. Dent JA. AMEE Guide No 26: clinical teaching in ambulatory care settings: making the most of learning opportunities with outpatients. Med Teach. 2005 Jun;27(4):302-15. https://doi.org/10.1080/01421590500150999

6. Dent JA, Harden RM. A practical guide for medical teachers (2nd ed.). Edinburgh: Elsevier Churchill Livingstone. 2005.

7. Amini A, Alizadeh M, Farzaneh F. Ambulatory medical education in educational centers of Tabriz school of medicine, Intern's point of view. Iranian Journal of Medical Education. 2002;7:19-21.

8. Shaban Yamchi N. [Attitude of Gps' abaut ambulatory. clinics.] 9th Congress of Medical Education. Yazd: University of Medical Sciences; 2008: [In Persian].

9. Bazazi N, Falahi G, Yavari A, Houshmand B. Medical students' viewpoints about the quality of education in outpatient clinics in Hamadan University of Medical Sciences in 2007: Iranian Journal of Medical Education, Summer 2011;11(2):167-173.

10. Avizhgan M, Farzanfar E, Najafi MR, Shams B, Ashoorion V. Ambulatory education quality in Al-Zahra Hospital clinics in Isfahan, View of clerkships students and interns. Iranian Journal of Medical Education (Special Issue on educational development). Winter 2010;10(5):896-905.

11. Shams B, Jamshidian S, Changiz T. Educational Challenges in Ambulatory Pediatrics Teaching Programs Based on the Experiences of Interns and Attends: a Qualitative Study: A qualitative study, Journal of Strides in Development of Medical Education. 2010;7(2):81-92.

12. Khorasani G, Mahmoudi M, Vahidshahi K, Shahbaznejad L, Ghafari M. Evaluation of Faculty Members' and Students' Attitude Towards Ambulatory Teaching Quality, School of Medicine, Mazandaran University of Medical Sciences, 2007. Journal of Mazandaran University of Medical Sciences. 2007;17(58):87-100.

13. Anbari Z, Ramezani M. The obstacles of clinical education and strategies for the improvement of quality of education at Arak University of Medical Sciences in 2008. Arak Medical University Journal (AMUJ. Summer 2010;13(2):110-118.

14. Mortazavi A, Razmara A. The satisfaction of medical clerkship students and interns with education in sectors, emergency department, outpatient centers in hospital and in the society of Isfahan University of Medical Sciences. Iranian Journal of Medical Education. 2002;3:49-52.

15. Amini M, Ghanavatipoor, Omidvari. [KAP survey regard. The most common disease, Jahrom.] Medical Education. Kerman: University of Medical Sciences. 2007:98. [In Persian]

16. Jacobson EW, Keough WL, Dalton BE, Giansiracusa DF. A comparison of inpatient and outpatient experiences during an internal medicine clerkship. Am J Med. 1998;104(2):159-62. https://doi.org/10.1016/S00029343(97)00343-4

17. Irby DM. Teaching and learning in ambulatory care settings: a thematic review of the literature. Acad Med. 1995;70(10):898-931. https://doi.org/10.1097/00001888-199510000-00014

18. Masood J, Wood D, Calleary J, Wiseman O, Lane T, Barua JM. The need for supervised training in urology outpatients:A case for restructuring. BJU Int. 2006;98(6):1144-5. https://doi.org/10.1111/j.1464410X.2006.06353.x

19. Zali MR, Mahdavi M S, Nobakht Haghighi A, Noroozi A, Akbari Ghamsari A. The causes of patients' satisfaction and complaints of physicians, Abstract book of 11th international conference on Geographic Medicine and and the first conference on Ambulatory Education, Shiraz University of Medical Sciences: 105.

20. Kalet A, Pugnaire MP, Cole-Kelly K,Janicik R, Ferrara E, Schwartz MD, Lipkin M Jr, Lazare A. Teaching communication in clinical clerkships: models from the macy initiative in health communications. Acad Med. 2004;79(6):511-20. https://doi.org/10.1097/00001888-200406000-00005 
21. Sievers $B$, Wolf $S$. Achieving clinical nurse specialist competencies and outcomes through interdisciplinary education. Clin Nurse Spec. 2006;20(2):75-80. https://doi.org/10.1097/00002800-200603000-00008

22. Scott I, Sazegar P. Why community physicians teach students (or not): barriers and opportunities for preceptor recruitment. Med Teach. 2006;28(6):563-5. https://doi.org/10.1080/01421590600627375

23. Lesky LG, Hershman WY. Practical approaches to a major educational challenge, training students in the ambulatory settings. Arch Intern 1995;155(9):897-904. https://doi.org/10.1001/archinte.1995.00430090022004

24. Alizade M, Sadeghi Hasan Abadi A, Tabatabii HR, Sharifi B. Opinion of general physicians of urban health center about ambulatory medical education. Abstract book of 11th International Geographic Medicine about Ambulatory education, Shiraz, Iran:116.

25. Wolpaw TM, Wolpaw DR, Papp KK, SNAPP S. A learner-centered model for outpatient education. Acad Med. 2003;78(9):893-8. https://doi.org/10.1097/00001888-200309000-00010

26. Lubetkin EI, Krackov SK, Storey-Johnson. The use of questionnaires to assess achievement of course goals in medical students' longitudinal community based clinical experiences. Acad Med. 1999;74:1316-9. https://doi.org/10.1097/00001888-199912000-00014

$\diamond \diamond \diamond \diamond \diamond \diamond \diamond$

http://www.ejgm.co.uk 